\title{
Intratumoral injection of PKR shRNA expressing plasmid inhibits B16-F10 melanoma growth
}

\author{
NAYARA DELGADO ANDRÉ ${ }^{1}$, VIVIANE ALINE OLIVEIRA SILVA ${ }^{2}$, \\ MARIA ANGELICA EHARA WATANABE ${ }^{3}$ and FERNANDO LUIZ DE LUCCA ${ }^{2}$ \\ ${ }^{1}$ Federal University of São João del-Rei, 35501296 Divinópolis, MG; \\ ${ }^{2}$ Department of Biochemistry and Immunology, Ribeirão Preto Medical School, University of São Paulo, \\ 14049-900 Ribeirão Preto, SP; ${ }^{3}$ Department of Pathological Sciences, Biological Sciences Center, \\ State University of Londrina, 86057-970 Londrina, PR, Brazil
}

Received June 16, 2014; Accepted August 4, 2014

DOI: $10.3892 /$ or.2014.3410

\begin{abstract}
The RNA-dependent protein kinase (PKR) is a serine/threonine kinase that is involved in the regulation of important cell processes such as apoptosis, signal transduction, cell proliferation and differentiation. However, the role played by PKR in cancer remains controversial. RNA interference (RNAi) has currently become an important technique in understanding gene function. Previously, we showed that PKR shRNA downregulates PKR expression in B16-F10 melanoma cells and reduces the metastatic potential of these tumor cells. In the present study, we examined the effect of the intratumoral injection of PKR shRNA-expressing plasmid on the growth of B16-F10 melanoma in mice. The results showed that this treatment significantly reduced tumor growth. Thus, these findings suggested that PKR acts as a tumor suppressor, a finding that is consistent with our previous study on the experimental model of metastasis. Moreover, the results suggested that this effect may be mediated by the transcription factor $\mathrm{NF}-\kappa \mathrm{B}$. The present study confirmed the hypothesis that the direct administration of RNAi-based therapeutics in the target tumor is a promising approach for overcoming the obstacles of systemic delivery. The results also suggested that the intratumoral injection of PKR shRNA-expressing vector is a novel therapeutic approach for human solid tumors such as cutaneous melanoma and breast cancer, since PKR is overexpressed in these tumors.
\end{abstract}

Correspondence to: Professor Fernando Luiz De Lucca, Department of Biochemistry and Immunology, Ribeirão Preto Medical School, University of São Paulo, 14049-900 Ribeirão Preto, SP, Brazil

E-mail: fldlucca@fmrp.usp.br

Key words: RNAi, PKR, B16-F10 melanoma, intratumoral injection, tumor growth

\section{Introduction}

The RNA-dependent protein kinase (PKR) is a serine/threonine kinase that was originally identified as a component of the interferon (IFN)-induced anti-viral response $(1,2)$. In response to viral infection, IFN induces the expression of a number of genes, including the human PKR gene. The anti-viral action of PKR is due to its activation by viral double-stranded RNA (dsRNA) which results in the phoshorylation of the $\alpha$-subunit of eukaryotic translational initiation factor 2 (eIF $2 \alpha$ ) with the subsequent shut-down of protein synthesis and inhibition of virus replication. It was demonstrated that PKR is ubiquitously expressed and can also be activated by cellular RNAs $(3,4)$ and proteins $(5,6)$, suggesting that the function of PKR is beyond the anti-viral defense.

Several studies have shown that PKR plays a role in the regulation of important cell processes such as apoptosis, signal transduction, cell proliferation and differentiation $(1,4,7,8)$. It has been reported that PKR acts as a tumor suppressor or stimulator protein, depending on the tumor type $(1,7,8)$. The role of PKR in cancer has been extensively studied, however, the results are controversial. In a previous study, we showed that a point mutation in the RNA-binding domain I results in the loss of PKR activity in acute lymphoblastic leukemia (9). By contrast, PKR silencing by RNA interference (RNAi) significantly reduced the number of pulmonary metastatic nodules in the B16-F10 melanoma. In that experimental model of metastasis, our findings suggested that the effect of PKR knockdown is mediated by the transcription factor NF- $\mathrm{KB}$ through the reduction of the phosphorylation of its inhibitor I $\kappa$ B $\beta$ by PKR (10).

RNAi has become a powerful tool for investigating gene function in mammalian cells $(10,11)$. The potential therapeutic of RNAi technology has also been explored in cancer since RNAi is able to selectively knockdown critical genes involved in cell proliferation (12). The RNAi technology holds promise for cancer treatment, however, a number of obstacles remain to be overcome before RNAi can be used in the clinic. Notably, the main challenge is to develop methods to specifically deliver RNAi to tumor cells. In the last few years, several strategies have been used to surmount this barrier (13-15) and 
Table I. Sequences of shRNA oligonucleotides.

\begin{tabular}{|c|c|c|}
\hline shRNA & Target position ${ }^{\mathrm{a}}$ & Sequence \\
\hline PKR-1 & 24 & 5'-ACGGAGGGCGAATAGATTT-3' \\
\hline PKR-2 & 320 & 5'-AAACGCTGCAGCCAAATTA-3' \\
\hline PKR-3 & 998 & 5'-ACTCAATCACGTCAACATT-3' \\
\hline Scrambled & - & 5'-ACGGAGGGCGAATAGATTT-3' \\
\hline
\end{tabular}

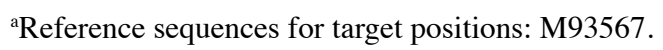

the intratumoral injection of RNAi emerges as a promising approach in the case of solid tumors (16).

In the present study, we investigated the effect of the intratumoral PKR short hairpin (shRNA)-expressing plasmid on the growth of B16-F10 melanoma in C57BL/6 mice. Since the effect of PKR on B16-F10 melanoma cells is mediated by $\mathrm{NF}-\kappa \mathrm{B}$, we also examined the level of its inhibitor I $\kappa \mathrm{B} \beta$ in the B16-F10 melanoma cells following the in vivo knockdown of PKR expression.

\section{Materials and methods}

Culture of tumor cells. B16-F10 melanoma cells were plated in tissue culture flasks and cultured in RPMI-1640 medium (Life Technologies, Carlsbad, CA, USA) supplemented with $10 \%$ inactivated fetal calf serum (Life Technologies), $2 \mathrm{mM}$ L-glutamine (Life Technologies) and 1\% penicillin/streptomycin (100 U/ml; Life Technologies) in a humidified incubator at $37^{\circ} \mathrm{C}$ and $5 \% \mathrm{CO}_{2}$.

Target sequence selection of PKR $\mathrm{mRNA}$ and plasmid vector construction. Three shRNAs targeting murine PKR and one scrambled shRNA (used as a control) with sense and antisense sequences were used. The selection of shRNA sequences was based on the shRNA Target Finder and Design Tool available at Dharmacon website. Each shRNA contains a sense strand of 19 nucleotides followed by a short spacer (AAGTTCTCT), and an antisense strand and stop signal (TTTTT) for RNA polymerase III.

siRNA sequences were selected a Blast search. The selected siRNA sequences were expressed against sequence tag libraries to ensure that only a single gene was targeted. A predicted secondary structure of the intended mRNA was assessed to avoid a steric hindrance of its binding. Each freeze-dried shRNA was reconstituted with RNase-free water to prepare a stock solution. Screening for the two inserts was performed by digestion with PstI (Promega, Madison, WI, USA). The targeting sequence and location of each shRNA in PKR cDNA is shown in Table I.

Transfection of B16-F10 melanoma cells. B16-F10 melanoma cells were plated in tissue culture flasks at a density of $7 \times 10^{5}$ cells. After an overnight incubation and a confluence of $\sim 70-80 \%$, the cells were transfected with $30 \mu \mathrm{g}$ of each PKR shRNA (PKR-1, PKR-2 and PKR-3 shRNA) or scrambled shRNA using $30 \mu \mathrm{l}$ of Lipofectamine 2000 (Life Technologies). The plasmid and Lipofectamine 2000 were diluted in serum-free medium, left at room temperature for $5 \mathrm{~min}$, mixed immediately, and incubated for $20 \mathrm{~min}$ at room temperature at a v/w ratio of liposomes to shRNA of 1:1. The culture medium was removed and the shRNA-lipid complex (1.5 ml total volume) was added. The transfection efficiency $(\sim 75-80 \%)$ was evaluated using green fluorescent protein (GFP).

We examined whether the three PKR shRNAs were effective in reducing PKR expression in cultured B16-F10 cells at $48 \mathrm{~h}$ after transfection when the cells were lysed and the amount of PKR mRNA as well as the amount of PKR protein were measured.

RNA isolation. Total cellular RNA was extracted using TRIzol LS reagent (Life Technologies). Cellular RNA in the aqueous phase was transferred to sterile RNAse-free $1.5-\mathrm{ml}$ microcentrifuge tubes and precipitated by adding an equal volume of isopropanol. Centrifugation at $10,000 \mathrm{rpm}$ for 10 min was then performed. The pellets were washed with $70 \%$ ethanol, air-dried and ressuspended in DEPC water. RNA concentrations were determined by spectrophotometric absorbance at $260 \mathrm{~nm}$. The quality of extracted RNA was determined by electrophoresis. RNA $(1 \mu \mathrm{g})$ was boiled in formamide loading buffer and snap cooled on ice. Samples were subjected to electrophoresis with $1 \%$ agarose gels in $1 \mathrm{X}$ TBE buffer ( $89 \mathrm{mM}$ Tris-HCl, $2.5 \mathrm{mM}$ EDTA, and $89 \mathrm{mM}$ boric acid). Nucleic acids were visualised by ethidium bromide staining and observed under ultraviolet light. The presence of intact $28 \mathrm{~S}$ and $18 \mathrm{~S}$ rRNA bands showed good quality cellular RNA. The RNA preparations were used for semi-quantitative RT-PCR.

Analysis of PKR expression by reverse transcription-PCR. Primer pairs designed to amplify PKR and $\beta$-actin were synthesized by IDT (Integrated DNA Technologies, Coralville, IA, USA). The primer sequences used included: PKR, sense, 5'-GTGGACATCTTTGCTTTGGGCCTT-3' and antisense, 5'-TGTTCCTCCATTCAGCCAAGGTCT-3' (GenBank accession no. M93567); $\beta$-actin, sense, 5'-TGGAATCCTGTGGCA TCCATGAAAC-3' and antisense, 5'-TAACGCAGCAGT AACAGTCCG-3' (GenBank accession no. BC014861). Total cellular RNA was extracted using TRIzol reagent (Life Technologies) and reverse-transcribed with $0.5 \mu \mathrm{g}$ of the oligodT primer, 1 unit of reverse transcriptase, 1 unit of RNase inhibitor, $5 \mu \mathrm{l}$ of $5 \mathrm{X}$ buffer and $4 \mu \mathrm{l} \mathrm{MgCl}_{2}$ (Life Technologies). We used $2 \mu \mathrm{l}$ of each reaction for PCR in $2 \mu \mathrm{l}$ of sense and antisense primers, respectively, $0.75 \mu \mathrm{l}$ of $\mathrm{MgCl}_{2}$ (25 mmol/l), 
$2.5 \mu \mathrm{l}$ of deoxynucleotide triphosphates (1.25 mM), $2.5 \mu \mathrm{l}$ of 10X PCR buffer, and 1 unit of Taq DNA polymerase in a $25-\mu 1$ reaction volume. $\beta$-actin was used as a control to assess the sample integrity and to normalize posterior results. PCR conditions for $\beta$-actin were 4 -min denaturation at $94^{\circ} \mathrm{C}, 35$ cycles of $1 \mathrm{~min}$ at $94^{\circ} \mathrm{C}, 1 \mathrm{~min}$ at $52^{\circ} \mathrm{C}$ and $2 \mathrm{~min}$ at $72^{\circ} \mathrm{C}$, and 10-min elongation at $72^{\circ} \mathrm{C}$ in a thermocycler (Abgene, Epsom, UK). PCR conditions for PKR were 4-min denaturation at $94^{\circ} \mathrm{C}, 37$ cycles of $1 \mathrm{~min}$ at $94^{\circ} \mathrm{C}, 1 \mathrm{~min}$ at $67^{\circ} \mathrm{C}$ and $1 \mathrm{~min}$ at $72^{\circ} \mathrm{C}$, and $10-\mathrm{min}$ elongation at $72^{\circ} \mathrm{C}$ in a thermocycler (Abgene). PCR products of $\beta$-actin (364 bp) and PKR (290 bp) were analysed by electrophoresis in a $1.5 \%$ agarose gel and visualized using UV fluorescence after staining with ethidium bromide. Quantification of PKR bands was performed by using ImageQuant software, version 3.3 (Molecular Dynamics, Sunnyvale, CA, USA). The gray scale ratio of PKR/ $\beta$-actin was calculated and the results were expressed as a percentage. The clone with the highest inhibition of PKR expression was selected for in vivo studies.

Western blot analysis. B16-F10 melanoma cells were washed with ice-cold Tris-buffered saline (TBS) and lysed with 3 volumes of lysis buffer consisting of $20 \mathrm{mM}$ Tris- $\mathrm{HCl}$ (pH 7.6), 50 mM KCl, 400 mM NaCl, 1 mM EDTA, 0.2 mM phenylmethylsulfonyl fluoride, aprotinin ( $2 \mu \mathrm{g} / \mathrm{ml})$, leupeptin $(2 \mu \mathrm{g} / \mathrm{ml}), 1 \mathrm{mM}$ dithiotreitol, $1 \%$ Triton X-100 and $20 \%$ glycerol. The lysates were centrifuged at $10,000 \mathrm{rpm}$ for $20 \mathrm{~min}$ and the supernatant was stored at $-70^{\circ} \mathrm{C}$. The soluble proteins were then measured according to the Lowry method. $\beta$-actin was used as a loading control. Total cellular protein $(30 \mu \mathrm{g})$ was separated by electrophoresis through a $10 \%$ SDS-PAGE resolving gel with an SDS-PAGE stacking gel. After electrophoresis, the proteins were transferred onto a Hybond-C supported nitrocellulose membrane (GE Healthcare, Little Chalfont, UK) by electroblotting for $4 \mathrm{~h}$ at $45 \mathrm{~V}, 25^{\circ} \mathrm{C}$, in transfer buffer $(3.94 \mathrm{~g}$ Tris- $\mathrm{HCl}, 18.80 \mathrm{~g}$ glycine, $240 \mathrm{ml}$ methanol, and $10 \%$ SDS). The membranes were blocked with $10 \%$ dried milk in TBS $(20 \mathrm{mM}$ Tris, and $500 \mathrm{mM}$ $\mathrm{NaCl}$ ) at room temperature overnight, washed twice and then incubated at room temperature with mouse anti-PKR monoclonal antibody, rabbit anti-I $\kappa \mathrm{B} \beta$ polyclonal antibody (Santa Cruz Biotechnology Inc., Santa Cruz, CA, USA) or mouse anti- $\beta$-actin monoclonal antibody (Santa Cruz Biotechnology) in TBS buffer for $80 \mathrm{~min}$. The membrane was washed in TBS 1X Tween-20 for $20 \mathrm{~min}$, and secondary anti-mouse antibodies or anti-rabbit antibodies labeled with horseradish peroxidase (GE Healthcare) were added and the membrane was incubated at room temperature for $60 \mathrm{~min}$. The membrane was washed twice in TBS-T for $20 \mathrm{~min}$ and in TBS for $5 \mathrm{~min}$. Antibody-labeled protein bands were visualized with ECL detection reagents (GE Healthcare) according to the manufacturer's instructions. Quantification of bands was performed by using the ImageQuant software, version 3.3 (Molecular Dynamics) and the results were expressed as a percentage.

Transfection of B16-F10 melanoma cells for in vivo assays. For in vivo experiments, B16-F10 melanoma cells were transfected with PKR-2 or scrambled shRNA for 5 h. Following transfection, the cells were detached with EDTA, washed twice in PBS and then resuspended in RPMI at $2.0 \times 10^{6}$ cells $/ \mathrm{ml}$. Cell viability was assessed by trypan blue staining and was $>95 \%$.

Animals. All the protocols involving animals were reviewed and approved by our Institutional Animal Care Committee. C57BL/6 mice, weighing 20-25 g, that were raised at the Central Animal Laboratory of the School of Medicine of Ribeirão Preto, SP, Brazil were used.

Tumorigenic assay. Based on the in vitro findings, PKR-2 shRNA was selected for the in vivo experiments. Tumor cells transfected with PKR-2 or scrambled shRNA for $5 \mathrm{~h}$ were harvested with EDTA, washed with RMPI, and resuspended in serum-free DMEM. The cells were then inoculated subcutaneously $\left(4.0 \times 10^{5}\right.$ cells) into the right flank of mice $(n=10$ per group). The mice were sacrificed 14 days post-inoculation, tumors were excised and weighed on a microbalance Sartorius Supermicro (model S4; Sartorius, Goettingen, Germany).

Intratumoral injection of PKR-2 shRNA. A total of $4.0 \times 10^{5}$ cells $/ \mathrm{ml}$ melanoma cells were subcutaneously inoculated in $0.2 \mathrm{ml}$ of RPMI-1640 medium into the right flank of C57BL/6 mice ( $n=10$ per group). After 7 days of tumor inoculation mice received a single intratumoral injection of $2 \mu \mathrm{g}$ of shRNA PKR-2 complexed with $2 \mu \mathrm{l}$ of Lipofectamine 2000 dissolved in $50 \mu \mathrm{l}$ of RPMI. Some mice received an intratumoral injection of $2 \mu \mathrm{g}$ scrambled shRNA-expressing plasmid complexed with $2 \mu \mathrm{l}$ of Lipofectamine 2000 as a negative control. The mice were sacrificed 7 days aftter intratumoral injection and the tumors was weighed.

Statistical analysis. Data are expressed as means \pm SD. Student's t-test was used to compare treated with control groups. $\mathrm{P}<0.05$ was considered significant.

\section{Results}

Transfection of B16-F10 melanoma cells with PKR-2 shRNA-expressing plasmid results in the degradation of $P K R$ $m R N A$. To reduce the expression of PKR mRNA in B16-F10 melanoma cells, three PKR shRNAs were designed. Each PKR shRNA was annealed and ligated into the psiSTRIKE vector controlled by Pol III U6 promoter. The tumor cells were transfected at 5, 24 and $48 \mathrm{~h}$ with the plasmid-based PKR-1, PKR-2, PKR-3 shRNA or scrambled shRNA-expressing plasmids with Lipofectamine 2000. Following transfection, PKR degradation was monitored by RT-PCR. Fig. 1 shows that only the plasmid-based PKR-2 shRNA significantly reduced the level of PKR mRNA after $48 \mathrm{~h}$ of transfection and this effect continued for up to 4 days (data not shown).

Transfection of B16-F10 melanoma cells with PKR-2 shRNA-expressing plasmid reduces the level of PKR protein. The effect of the transfection of B16-F10 melanoma cells with the three PKR shRNA-expressing plasmids was also monitored by western blot analysis. The downregulation of PKR protein expression was also significantly detected only with the plasmid-based PKR-2 shRNA at $48 \mathrm{~h}$ after transfection (Fig. 2). This effect was observed for up to 4 days and the 


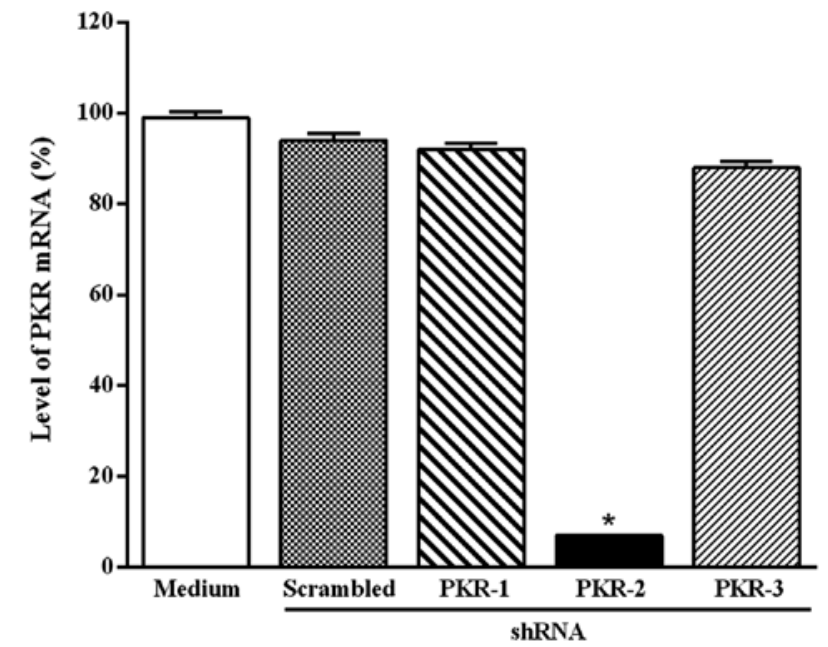

Figure 1. PKR mRNA expression in B16-F10 melanoma cells transfected with PKR-specific shRNAs or scrambled shRNA. Tumor cells were cultured and transfected as described in Materials and methods and the level of PKR mRNA at $48 \mathrm{~h}$ after transfection was determined by RT-PCR. $\beta$-actin was used as a loading control. The level of PKR mRNA in tumor cells incubated with RPMI medium was set as $100 \%$. Results are expressed as the means $\pm \mathrm{SD}$ of three independent experiments and the bands are representative of one typical experiment. ${ }^{*} \mathrm{P}<0.001$.

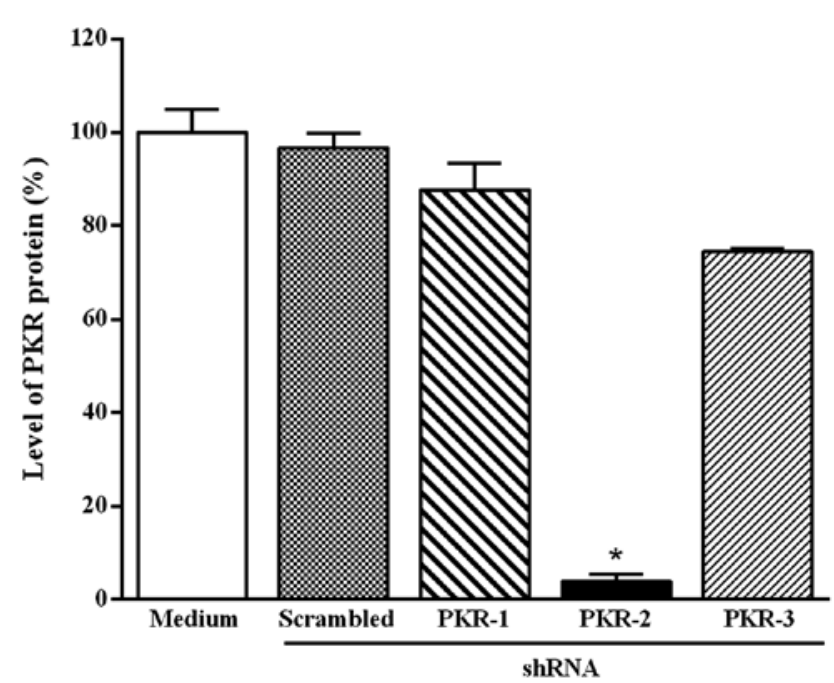

Figure 2. Level of PKR protein in B16-F10 melanoma cells transfected with PKR-specific shRNAs or scrambled shRNA. Tumor cells were cultured and transfected as described in Materials and methods. After $48 \mathrm{~h}$ of transfection, the level of PKR protein was determined by western blot analysis. The $\beta$-actin protein was used as a loading control. The level of PKR protein in tumor cells incubated with RPMI medium was set as $100 \%$. Results are expressed as the mean $\pm \mathrm{SD}$ of three independent experiments and the bands are representative of one typical experiment. ${ }^{*} \mathrm{P}<0.001$.

reduction of PKR protein level at 5 and $24 \mathrm{~h}$ after transfection was smaller than that at $48 \mathrm{~h}$ (data not shown).

Transfection of B16-10 melanoma cells with the PKR-2 shRNA-expressing plasmid inhibits tumor growth. Based on results shown in Figs. 1 and 2, the effect of the transfection of B16-F10 melanoma cells with the PKR-2 shRNA-expressing plasmid on tumor grow th was subsequently investigated. The transfected tumor cells were injected subcutaneously into C57BL/6 mice. The animals were sacrificed 14 days after

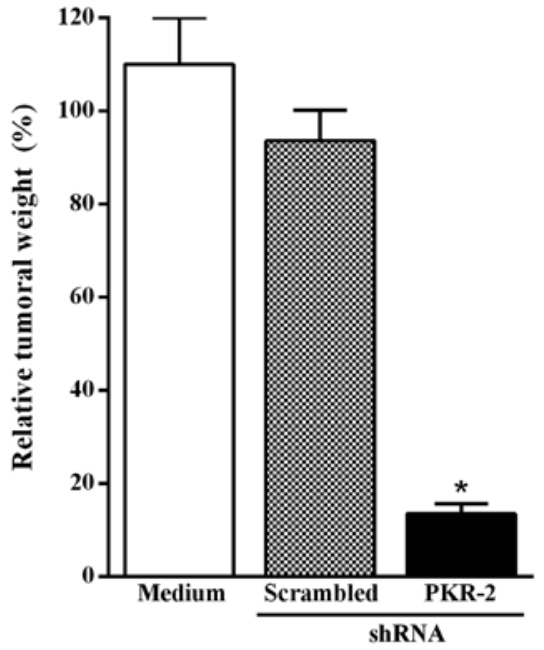

Figure 3. Effect of the transfection of B16-F10 melanoma cells on tumor growth in mice. Mice ( $n=10$ per group) were subcutaneously inoculated with tumor cells incubated with medium, and transfected with the PKR-2 or scrambled shRNA-expressing plasmids. Mice were sacrificed and tumors were excised and weighed. Results are expressed as the means \pm SD and the mean of the tumor weight corresponding to control group was set as $100 \%$. Data of one representative experiment of three are shown. ${ }^{*} \mathrm{P}<0.001$.

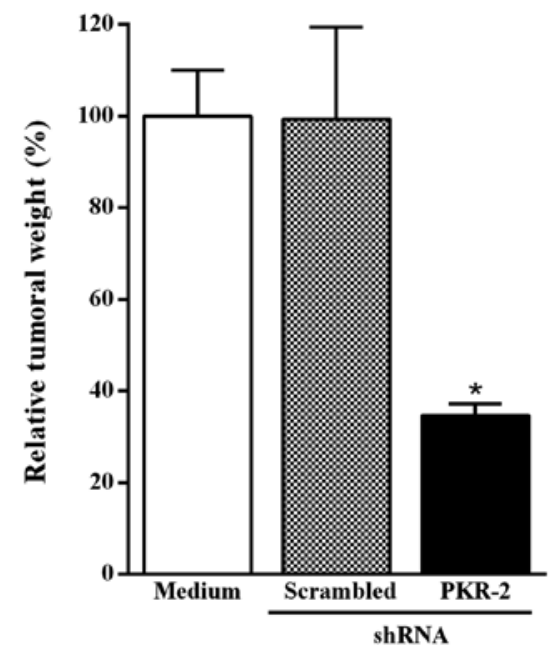

Figure 4. Effect of intratumoral injection of PKR-specific shRNA or scrambled shRNA-expressing plasmids on tumor growth in C57BL/6 mice. B16-F10 melanoma cells were subcutaneously inoculated into C57BL/6 mice ( $n=10$ per group). After 7 days of tumor cell inoculation, the mice received a single intratumoral injection of PKR-2 or scrambled shRNA. Mice were sacrificed 7 days after injection, tumors were removed and weighted. Results are expressed as the means \pm SD and the mean of the tumor weight corresponding to control group was set as $100 \%$. Data of one representative experiment of three are shown. ${ }^{*} \mathrm{P}<0.001$.

the inoculation of B16-F10 melanoma cells and tumors were excised and weighed. Fig. 3 shows that tumor growth was significantly inhibited when B16-F10 melanoma cells were transfected with the PKR-2 shRNA-expressing plasmid as compared to tumor cells transfected with the plasmid-based scrambled shRNA.

Intratumoralinjection of the PKR-2 shRNA-expressing plasmid inhibits B16-F10 melanoma growth. To investigate the effect of the intratumoral injection of the PKR-2 shRNA-expressing 


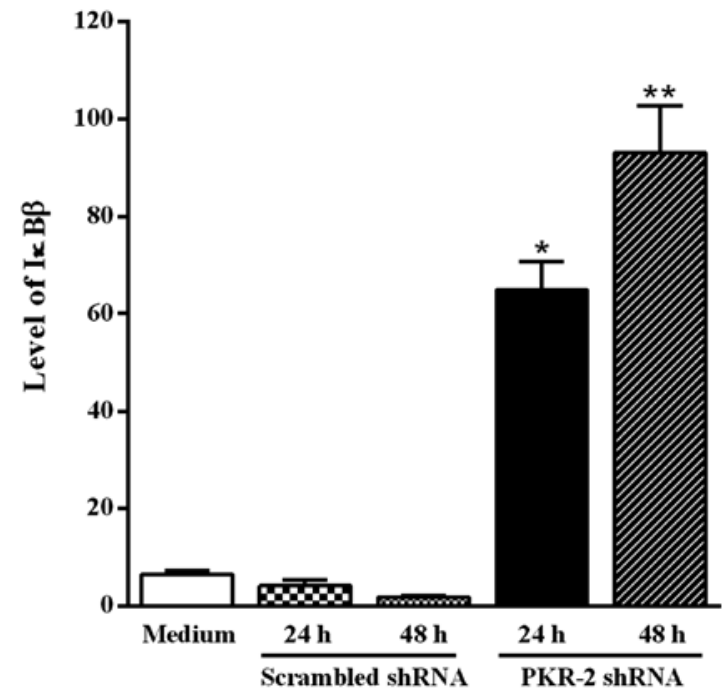

Figure 5. Effect of transfection of B16-F10 melanoma cells on the IкB $\beta$ level. Tumor cells were transfected with the plasmid-based PKR-2 shRNA at 24 and $48 \mathrm{~h}$ and the level of IкB $\beta$ was determined by western blot analysis. The $\beta$-actin protein was used as a loading control. Quantification of bands was performed by using the ImageQuant software and the level of IкB $\beta$ in tumor cells incubated with RPMI medium was set as 1. Results are expressed as the means $\pm \mathrm{SD}$ of three independent experiments and the bands are representative of one typical experiment. ${ }^{*} \mathrm{P}<0.001$

plasmid on tumor growth, mice were inoculated subcutaneously with B16-F10 melanoma cells. Fig. 4 shows that the reduction of tumor weight was significantly increased in mice that had received a single intratumoral injection of the PKR-2 shRNA-expressing plasmid as compared to animals injected with the plasmid-based scrambled shRNA.

Transfection of B16-F10 melanoma cells with PKR-2 shRNAexpressing plasmid increases the level of $I \kappa B \beta$. PKR is able to activate IKK, which phosphorylates the inhibitor I $\kappa \mathrm{B} \beta$ of the transcription factor NF- $\kappa \mathrm{B}$. Moreover, the phosphorylation of $\mathrm{I} \kappa \mathrm{B} \beta$ results in its degradation. To determine whether downregulation of the activated PKR by the PKR-2 shRNA was accompanied by an increase of the I $\mathrm{B} \beta \beta$ level, tumor cells were transfected with the PKR-2 shRNA-expressing plasmid and western blot analysis was performed using the anti-I $\kappa \mathrm{B} \beta$ antibody. Fig. 5 shows that the I $\kappa \mathrm{B} \beta$ level was significantly increased in B16-F10 melanoma cells transfected with PKR-2 shRNA-expressing plasmid when compared to tumor cells transfected with the plasmid-based scrambled shRNA.

\section{Discussion}

RNAi-based therapy is known to be effective and elicit a gene silencing response, and that double-stranded RNA molecules must be delivered to the target cell. However, delivery of RNAi has been challenging and despite many efforts to overcome this obstacle, current approaches are limited to few clinical indications $(12,17)$. Over the last few years, attempts have been made to increase the efficacy of siRNA delivery including chemical modifications and nanoparticle-based encapsulation of siRNA $(18,19)$.

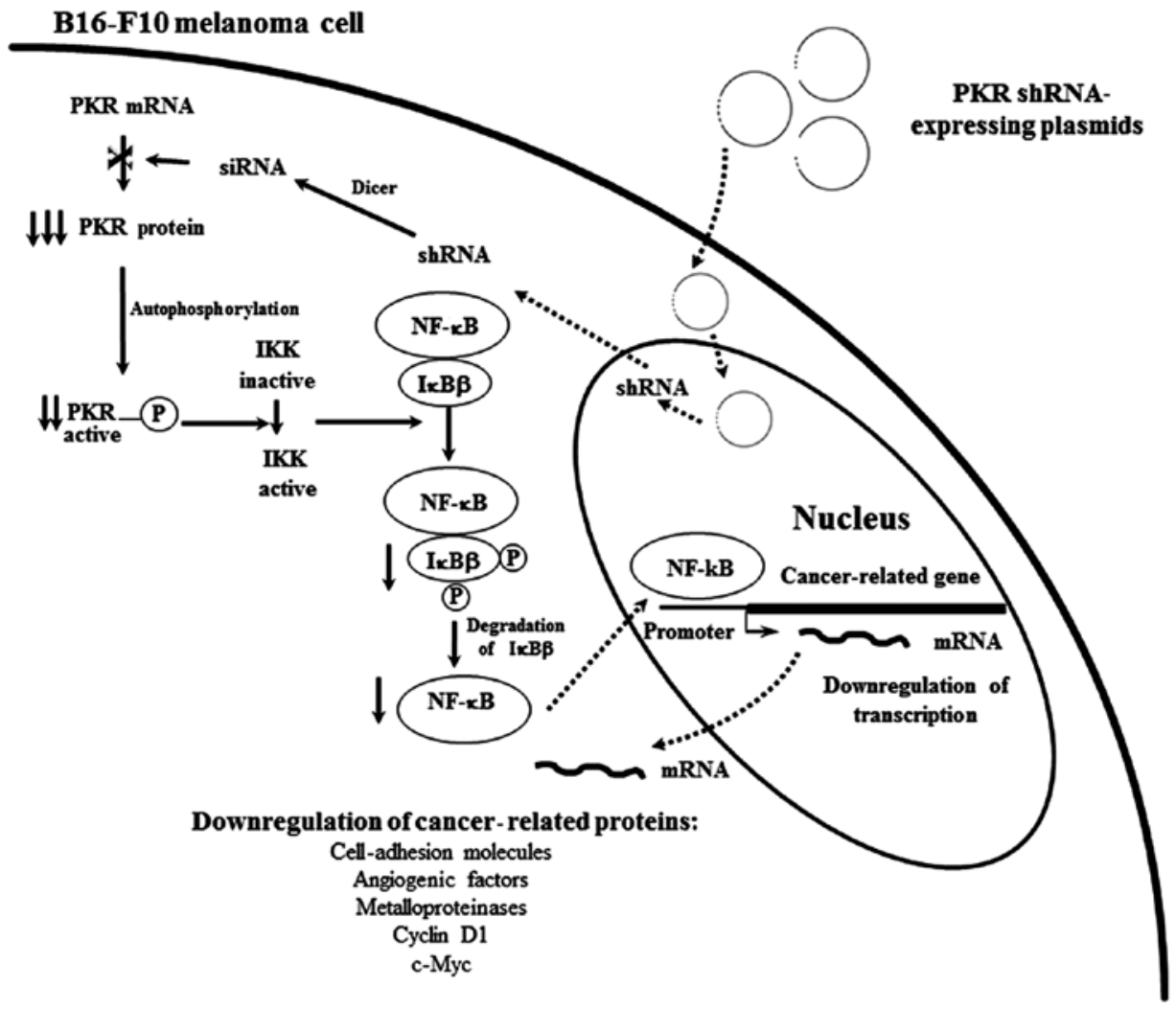

Figure 6. Overview of proposed molecular mechanism involved in the inhibition of B16-F10 melanoma growth after intratumoral injection of PKR-specific shRNA expressing plasmids. The following abbreviations were used: PKR, RNA-dependent protein kinase; shRNA, short hairpin RNA; siRNA, small

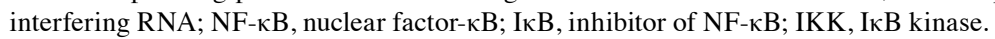


In the present study, RNAi technology was applied to elucidate the role played by PKR in B16-F10 melanoma since the function of this protein kinase in tumorigenesis remains controversial. A plasmid vector was employed for the expression of anti-PKR shRNA and the delivery was performed by intratumoral injection which is promising for solid tumors. Results of the present study show that transfection of the B16-F10 melanoma cells with the PKR-2-expressing plasmid was effective in inducing a statistically significant reduction of the levels of PKR mRNA and protein expression, whereas PKR-1 and PKR-3 shRNA had no effect. Therefore, the PKR-2 shRNA-expressing plasmid was selected for subsequent experiments. We then investigated whether transfection with the PKR-2 shRNA-expressing plasmid reduces the potential of B16-F10 melanoma cells to develop tumor following subcutaneous injection in mice. The results show that PKR silencing inhibits tumor growth, suggesting that PKR acts as a tumor supressor, a finding that is consistent with previous results using an experimental model of metastasis (10).

It is known that in cancer research, the results obtained in vitro may not be reproducible in vivo due to the complexity of biological systems. Thus, we investigated the effect of the intratumoral injection of the PKR-2 shRNA-expressing plasmid in the pre-established subcutaneous B16-F10 melanoma. We found that PKR silencing inhibits tumor growth when compared to animals injected with the plasmid-based scrambled shRNA. It is of note that this effect was obtained with only a single injection of the PKR-2 shRNA-expressing plasmid and this approach for RNAi delivery was effective for at least 7 days. Previous studies have demonstrated that shRNA expression vectors are able to sustain gene silencing in human cell lines $(16,20)$.

PKR is known to activate NF- $\kappa \mathrm{B}$ by directly phosphorylating its inhibitor $\mathrm{I} \kappa \mathrm{B} \alpha(21)$ or indirectly by activating the I $\mathrm{B}$ kinase (IKK) complex (22). The phosphorylated I $\mathrm{B}$ undergoes polyubiquitination which targets it for degradation by the ubiquitin-proteasome system, thereby releasing $\mathrm{NF}-\kappa \mathrm{B}$ to translocate to the nucleus. Notably, $\mathrm{NF}-\kappa \mathrm{B}$ regulates the transcription of genes involved in immuno-inflammatory responses, cell cycle progression, inhibition of apoptosis and cell adhesion, thus promoting carcinogenesis and cancer progression.

A notable finding of the present study was the observation that $\mathrm{I} \kappa \mathrm{B} \beta$ level is significantly increased in B16-F10 melanoma cells transfected with PKR-2 shRNA-expressing plasmid when compared to tumor cells transfected with the plasmid-based scrambled shRNA. This result suggests that the inhibition of B16-F10 melanoma growth due to PKR silencing may be mediated by the transcription factor NF- $\kappa \mathrm{B}$. It is known that the inhibition of the degradation of the $\mathrm{I} \kappa \mathrm{B} \beta$ inhibitor is an efficient mechanism to avoid the persistent activation of $\mathrm{NF}-\kappa \mathrm{B}(23,24)$. Recently, it was demonstrated that the okadaic acid-induced phosphorylation of I- $\kappa \mathrm{B} \alpha$ was mediated by PKR (25).

Based on results of the present study and our previous findings $(4,26,27)$, we suggest a molecular mechanism that may explain the finding that silencing PKR expression in B16-F10 melanoma cells by the intratumoral injection of the PKR shRNA-expressing plasmids results in the reduction of tumor growth. Uptake of the injected plasmids by tumor cells occurs (Fig. 6) and thus PKR shRNA are transcribed in the nucleus, export for the cytoplasm and are processed by Dicer to generate siRNA, which induces the specific degradation of PKR mRNA. Therefore, the level of PKR protein is decreased with the subsequent reduction of phosphorylated $\mathrm{I} \kappa \mathrm{B} \beta$, resulting in inhibition of the nuclear translocation of $N F-\kappa B$. Thus, the expression of cancer-related proteins with promoters containing NF- $\kappa \mathrm{B}$-binding sites such as c-myc, cyclin D1, cell adhesion molecules, angiogenic factors and metalloproteinases, were downregulated, which may result in the growth inhibition of pre-existing B16-F10 melanoma.

In conclusion, the present study validates the hypothesis that the direct administration of RNAi-based therapeutics into the target tumor is a promising approach for overcoming obstacles of systemic delivery. Our results also suggest that the intratumoral injection of PKR shRNA-expressing vector is a novel therapeutic approach for human solid tumors such as cutaneous melanoma and breast cancer since PKR is overexpressed in these tumors.

\section{Acknowledgements}

The present study was supported by FAPESP (06/57963-1). We would like to thank Cacilda D. Pereira and Zuleica A.S. Moraes for the technical assistance.

\section{References}

1. Clemens MJ and Elia A: The double-stranded RNA-dependent protein kinase PKR: Structure and function. J Interferon Cytokine Res 17: 503-524, 1997.

2. García MA, Gil J, Ventoso I, Guerra S, Domingo E, Rivas C and Esteban M: Impact of protein kinase PKR in cell biology: from antiviral to antiproliferative action. Microbiol Mol Biol 70: 1032-1060, 2006.

3. Murad JM, de Souza LR and De Lucca FL: PKR activation by a non-coding RNA expressed in lymphocytes of mice bearing B16 melanoma. Blood Cells Mol Dis 37: 128-133, 2006.

4. Watanabe MAE, Souza LR, Murad JM and De Lucca FL: Activation of the RNA dependent protein kinase (PKR) of lymphocytes by regulatory RNAs: implications for immunomodulation in HIV infection. Curr HIV Res 3: 329-337, 2005.

5. Patel RC and Sen GC: PACT, a protein activator of the interferoninduced protein kinase, PKR. EMBO J 17: 4379-4390, 1998.

6. Singh M and Patel RC: Increased interaction between PACT molecules in response to stress signals is required for PKR activation. J Cell Biochem 113: 2754-2764, 2012.

7. Williams BR: PKR: a sentinel kinase for cellular stress. Oncogene 18: 6112-6120, 1999

8. Marchal JA, Lopez GJ, Peran M, Comino A, Delgado JR, GarcíaGarcía JA, Conde V, Aranda FM, Rivas C, Esteban M and Garcia MA: The impact of PKR activation: from neurodeggeneration to cancer. FASEB J 28: 1965-1974, 2014.

9. Murad JM, Tone LG, Souza LR and De Lucca FL: A point mutation in the RNA-binding domain I results in decrease of PKR activation in acute lymphoblastic leukemia. Blood Cells Mol Dis 34: 1-5, 2005

10. Delgado-André N and De Lucca FL: Knockdown of PKR expression by RNAi reduces pulmonary metastatic potential of B16-F10 melanoma cells in mice: possible role of NF-kappaB. Cancer Lett 258: 118-125, 2007.

11. Gao L, Zhang L, Hu J, Li F, Shao Y, Zhao D, Kalvakolanu DV, Kopecko DJ, Zhao X and Xu DQ: Downregulation of signal transducer and activator of transcription 3 expression using vector-based small interfering RNAs suppresses growth of human prostate tumor in vivo. Clin Cancer Res 11: 6333-6341, 2005.

12. Deng Y, Wang CC, Choy KW, Du Q, Chen J, Wang Q, Li L, Chung TK and Tang T: Therapeutic potentials of gene silencing by RNA interference: principles, challenges, and new strategies. Gene 538: 217-227, 2014. 
13. Díaz MR and Vivas-Mejia PE: Nanoparticles as drug delivery systems in cancer medicine: emphasis on RNAi-containing nanoliposomes. Pharmaceuticals 6: 1361-1380, 2013.

14. Li CH, Parker A, Menocal E, Xiang S, Borodyansky L and Fruehauf JH: Delivery of RNA interference. Cell Cycle 5: 2103-2109, 2006.

15. Sakurai Y, Hatakeyama H, Sato Y, Hyodo M, Akita $H$ and Harashima H: Gene silencing via RNAi and siRNA quantification in tumor tissue using MEND, a liposomal siRNA delivery system. Mol Ther 21: 1195-1203, 2013.

16. Deharvengt SJ, Gunn JR, Pickett SB and Korc M: Intratumoral delivery of shRNA targeting cyclin D1 attenuates pancreatic cancer growth. Cancer Gene Ther 17: 325-333, 2010.

17. Fujita Y, Takeshita F, Kuwano K and Ochiya T: RNAi therapeutic platforms for lung diseases. Pharmaceuticals 6: 223-250, 2013.

18. Nikitenko NA and Prassolov VS: Non-viral delivery and therapeutic application of small interfering RNAs. Acta Naturae 5: 35-53, 2013.

19. Das J, Das S, Paul A, Samadder A, Bhattacharyya SS and Khuda-Bukhsh AR: Assessment of drug delivery and anticancer potentials of nanoparticles-loaded siRNA targeting STAT3 in lung cancer, in vitro and in vivo. Toxicol Lett 225: 454-466, 2014.

20. Paddison PJ, Caudy AA, Bernstein E, Hannon G and Conklin DS: Short hairpin RNAs (shRNAs) induce sequence-specific silencing in mammalian cells. Genes Dev 16: 948-958, 2002.
21. Kumar A, Haque J, Lacoste J, Hiscott J and Williams BR: Double-stranded RNA-dependent protein kinase activates transcription factor NF-kappa B by phosphorylating I kappa B. Proc Natl Acad Sci USA 91: 6288-6292, 1994.

22. Gil J, Alcamí J and Esteban M: Activation of NF-kappa B by the dsRNA-dependent protein kinase, PKR involves the I kappa B kinase complex. Oncogene 19: 1369-1378, 2000.

23. Thompson JE, Phillips RJ, Erdjument-Bromage H, Tempst $P$ and Ghosh S: I kappa B-beta regulates the persistent response in a biphasic activation of NF-kappa B. Cell 80: 573-582, 1995.

24. Lindgren H, Olsson AR, Pero RW and Leanderson T: Differential usage of IkappaBalpha and IkappaBbeta in regulation of apoptosis versus gene expression. Biochem Biophys Res Commun 301: 204-211, 2003.

25. Haneji T, Hirashima K, Teramachi J and Morimoto H: Okadaic acid activates the PKR pathway and induces apoptosis through PKR stimulation in MG63 osteoblast-like cells. Int J Oncol 42: 1904-1910, 2013.

26. De Lucca FL, Serrano SV, Souza LR and Watanabe MA: Activation of RNA-dependent protein kinase and nuclear factor-kB by regulatory RNA from lipopolysaccharide-stimulated macrophages: implications for cytokine production. Eur $\mathbf{J}$ Pharmacol 450: 85-89, 2002.

27. Watanabe MA, Rodrigues Souza L, Murad JM and De Lucca FL: Antitumor activity induced by regulatory RNA: possible role of RNA-dependent protein kinase and nuclear factor-kappa B. Eur J Pharmacol 465: 205-210, 2003. 